\title{
Bag Address Data Type
}

National Cancer Institute

\section{Source}

National Cancer Institute. Bag Address Data Type. NCI Thesaurus. Code C95687.

A data type comprised of an unordered collection of addresses. 